\title{
A MOBILIDADE CAMPO-CIDADE EM PEQUENOS MUNICÍPIOS: EM ANÁLISE OS DESLOCAMENTOS ROTINEIROS EM ARAPONGA, MG
}

\author{
Nayhara Freitas Martins GOMES ${ }^{1}$ \\ Ana Louise de Carvalho FIÚZA² \\ Neide Maria de Almeida PINTO ${ }^{3}$ \\ Paula Cristina Almeida Cadima REMOALDO
}

\section{Resumo}

A mobilidade tem sido objeto de numerosos estudos. No entanto, este fenômeno tem sido estudado como se ele fosse tipicamente citadino. Todavia, o deslocamento entre o campo e a cidade realizado pelos rurais de forma rotineira revela novas dimensões sociodemográficas dos pequenos municípios, pós-anos 1990 . O objetivo deste artigo foi, justamente, analisar a mobilidade campo-cidade em pequenos municípios, em sua faceta cotidiana, rotineira. O estudo foi realizado em um pequeno município de economia agrícola situado na Zona da Mata de Minas Gerais. Os resultados mostraram que a mobilidade rotineira dos rurais entre o campo e a cidade não se constituía em um fenômeno exclusivamente citadino. As idas à cidade estiveram relacionadas, prioritariamente, à esfera do consumo pessoal e aos modos de morar. A mobilidade dos rurais à cidade evidenciou, ainda, contornos de gênero e de renda. Os homens, adultos e aposentados, deslocavam-se mais para a cidade em função de possuírem acesso direto aos meios de transporte dentro da família. Já as senhoras aposentadas eram aquelas, dentre as mulheres, que mais se deslocavam. Contudo, tal deslocamento era realizado, invariavelmente, mediante gastos com táxi ou motorista para a cidade, diferentemente do que acontecia com os homens.

Palavras-chave: Mobilidade. Rurais. Pequenos municípios.

\footnotetext{
1 Doutoranda em Geografia na Universidade Federal de Minas Gerais (IGC/UFMG). Mestre em Extensão Rural na Universidade Federal de Viçosa (DER/UFV). Licenciada e Bacharela em Geografia (UFV). Av. Professor Magalhães Penido, 389, Bairro São Luis. Apt 104, CEP: 31270-700, Belo Horizonte/MG. E-mail: nayhara_martins@yahoo.com.br

2 Doutora em Ciências Sociais em Desenvolvimento, Agricultura e Sociedade (UFRRJ). Professora Associada II do Programa de Pós-Graduação em Extensão Rural (UFV) e Coordenadora do Grupo GERAR - Grupo de Estudos Rurais: agriculturas e ruralidades. Programa de Pós-Graduação em Extensão Rural - Departamento de Economia Rural; Av. Purdue, s/n, Edifício Edson Potsch Magalhães; Campus Universitário; Prédio Anexo. CEP: 36570-000; Viçosa/MG. E-mail: louisefiuza@ufv.br

3 Doutora em Ciências Sociais (PUC-SP). Professora Associada III do Programa de Pós-Graduação em Economia Doméstica (UFV) e Vice-Coordenadora do Grupo GERAR - Grupo de Estudos Rurais: agriculturas e ruralidades. Departamento de Economia Doméstica - Universidade Federal de Viçosa; Av. Peter Henry Rolfs s/n. Campus Universitário; CEP: 36570-000; Viçosa/MG. E-mail: nalmeida@ufv.br

4 Associate Professor with Habilitation. Co-Coordinator of Investigation Group "Space and Representations (SpaceR)". Director of Master in Geography - Planning and Management of Territory Institute of Social Sciences - Department of Geography -University of Minho -Portugal. Instituto de Ciências Sociais - Departamento de Geografia - Universidade do Minho. Campus de Azurém; CEP: 4800-058; Guimarães/Portugal. E-mail: premoaldo@geografia.uminho.pt
} 


\section{Abstract}

\section{Urban-rural mobility in small municipalities: analysis of the commute in Araponga, MG}

The mobility has been the object of numerous studies. However, this phenomenon has been studied as if it was only urban. Nevertheless, the routine displacement between the city and the country reveals new socio-demographic dimensions in small post-1990s municipalities. The objective of this article was to analyze the routine commute between rural and urban areas in small cities. The study was carried out in a small agricultural city, Araponga, situated in the "Forest Zone" of the state of Minas Gerais. The results showed that the rural-urban commute is not exclusive to large urban areas. The movements also displayed differences related to sex and income. Adult and retired males commuted more as they had direct access to the family means of transportation. On the other hand, retired women were the group that dislocated the most amongst females. However, their transportation was through taxis or drivers to the city, differently than the means of the males.

Key words: Mobility. Rural workers. Small municipalities.

\section{INTRODUÇÃO}

Este artigo teve por objetivo analisar o fenômeno da mobilidade entre o campo e a cidade não em termos do fenômeno referente à migração, mas na sua vertente cotidiana, relativa ao ir e vir dos rurais entre a "roça" e a "rua", a fim de trabalhar, estudar, buscar a prestação de serviços, comprar bens pessoais e de uso domésticos, dentre tantos outros fins. Bell et al (2010, p.202) chamam a atenção para o fato de que os estudos sobre a mobilidade têm sido priorizados como retratando um fenômeno característico dos centros urbanos e, sobretudo, das metrópoles. O estudo sobre a mobilidade no campo vêm sendo negligenciado, também, na ótica de Goodwin-Hawkins (2015, p.168), que alerta para o fato de haver, portanto, a desconsideração acerca da influência que a mobilidade exerce nas transformações dos modos de vida dos rurais, como aponta Milbourne (2014, p.327), que destaca, ainda, a sua influência para a fixação das pessoas em pequenos municípios. Na contemporaneidade, segundo Matos (2011, p.111), a mobilidade se intensifica pela facilidade de acesso aos meios de transporte e de comunicação que comprimem o espaço e o tempo, levando ao surgimento de espaços híbridos, fruto das interações entre os modos de vida rural e urbano.

Neste contexto, dar enfoque aos deslocamentos rotineiros realizados pelos rurais entre o campo e a cidade permite compreender a forma como vem se efetivando a mudança nos modos de vida das pessoas que residem nos pequenos municípios, com até 20.000 habitantes, os quais representam mais de $80 \%$ dos municípios brasileiros (VEIGA, 2004, p.80). Examinar o deslocamento campo-cidade realizado de forma rotineira pelos rurais é relevante, ainda, por permitir analisar os sincronismos e dissonâncias entre o modo de vida rural e urbano. O artigo que ora se apresenta é resultado de uma pesquisa de mestrado realizada em Araponga, um pequeno município, de economia cafeeira, localizado na Zona da Mata do Estado de Minas Gerais.

O presente artigo apresenta na próxima seção o debate teórico referente ao fenômeno da mobilidade em pequenos municípios. Após a apresentação da justificativa em relação a opção teórica adotada, apresentam-se os dados empíricos referentes às características dos diferentes tipos de deslocamentos realizados pelos rurais 
neste pequeno município de economia agrícola. Esta etapa de apresentação dos dados focaliza, particularmente, vieses de gênero e de diferenças geracionais relativos à mobilidade dos rurais.

\section{MARCO TEÓRICO}

Para Becker (1997, p.323) somos seres sociais e espaciais. Transitamos pelo espaço motivados por necessidades diversas. A mobilidade espacial e suas dinâmicas são inerentes à história do homem, se constituindo em uma forma de interação espacial integrante da existência, da reprodução e do processo de transformação social. Cresswell (2011, p.8) garante que a mobilidade além de ser geográfica é central para a experiência humana do mundo. Portanto, a mobilidade espacial se configura como condição para a existência dos indivíduos ou grupos. Entretanto, seria muito reducionista percebê-la apenas como simples deslocamento de pessoas, mercadorias, capital e informação no espaço. A mobilidade ao se referir à existência e reprodução social reflete as dissonâncias dos lugares de origem e destino, resultando em um julgamento valorativo assimétrico de um lugar em detrimento do outro. Merriman (2012, p.232) sugere que os trabalhos recentes sobre o fenômeno da mobilidade devem ir além das ideias convencionais de mensuração dos grandes fluxos, percebendo-a como um processo que molda ativamente as dinâmicas socioespaciais.

As "interações espaciais" constituem um amplo e complexo conjunto de deslocamentos de pessoas, mercadorias, capital e informação sobre o espaço geográfico (CORRÊA, 1997, p.279). Podem ser caracterizadas pela maior ou menor intensidade, por variações segundo a frequência de ocorrência e, conforme a distância e direção, motivadas por objetivos a serem alcançados e se realizarem através de diversos meios e velocidades. Neste sentido, há uma gama de exemplos correntes de interações espaciais e experiências socioespaciais, nas quais de certa forma, estamos envolvidos e que crescem em intensidade, densidade e ritmo carregando consigo dimensões materiais e imateriais. Urry (2007, p.269) sugere que os espaços estão econômica, política e culturalmente produzidos através das múltiplas mobilidades: de pessoas, como, também, de capital, de objetos, de sinais e de informações.

A integração do espaço geográfico se estabelece a partir da alteração da natureza, da intensidade e dos padrões espaciais da interação. O capitalismo industrial acentua a mobilidade acelerando a circulação de pessoas, mercadorias, capitais e informações, afetando diretamente os deslocamentos de curta e longa distância, entre os espaços de origem e os de destino. De acordo com Corrêa (1997, p.284), já no fim do século XIX, as interações espaciais mostravam-se marcadas pela superação do espaço pelo tempo. A instantaneidade e a simultaneidade conhecida hoje no âmbito da circulação de informações, não se aplicaram da mesma forma às mercadorias e às pessoas, em função daquela ser o resultado do progresso técnico decorrente da crescente demanda de comunicação. Demandante da aceleração do ciclo reprodutivo, o capital buscou sucessivos e mais eficientes meios de circulação e comunicação. De acordo com Marx (1984, p.778), o ciclo de reprodução do capital se constituiria no principal processo do Capitalismo que originaria direta ou indiretamente, grande parte das interações espaciais.

Milbourne (2007, p.385) concebe a mobilidade como um fenômeno que transcende o espaço, encontrando-se, também, onipresente no seio da sociedade. Segundo Sousa (2005, p.120), a mobilidade faz parte das pré-condições do desenvolvimento político e cultural de um povo, pois as pessoas necessitam estar em constante 
movimento para realizarem atividades relacionadas ao trabalho, ao lazer, à educação, às práticas religiosas, culturais, bem como aquelas referentes ao consumo de bens e serviços. Dessa forma, a situação espacial de cada sujeito pode facilitar ou dificultar esses deslocamentos. Os deslocamentos são necessários à reprodução da vida, sendo dependentes de fatores sociais, políticos e econômicos que variam no tempo e no espaço e consequentemente, as suas necessidades de transporte também são muito diferentes e estão diretamente ligadas às condições específicas de cada local (VASCONCELLOS, 2001, p.37). No que diz respeito, especificamente, ao deslocamento entre o campo e a cidade, estas porções espaciais têm as suas relações aproximadas em virtude da melhoria da malha viária e da diversificação das possibilidades de acesso aos meios de transporte. Mesmo nas pequenas cidades brasileiras este fenômeno vem se tornando visível, principalmente, a partir de fins dos anos 1980 (SOUZA, 2011, p.11).

De acordo com o Instituto Brasileiro de Geografia e Estatística (IBGE) as "cidades pequenas" são aquelas que possuem população inferior a 100.000 habitantes. Contudo, adotamos neste artigo a classificação da ONU (Organização das Nações Unidas), que é ainda mais restrita, atribuindo à pequena cidade um contingente populacional de até 20.000 mil habitantes. A justificativa pela preferência em relação à classificação da ONU se dá em função de entendermos que ela propicia um agrupamento mais uniforme dos municípios brasileiros do que o do IBGE. No caso do Brasil, aproximadamente $80 \%$ dos municípios não ultrapassam os 20.000 habitantes (VEIGA, 2004 , p.70) e dentro deste grupo os municípios com perfil agrícola representam quase a sua totalidade.

\section{DELINEANDO OS PERCURSOS METODOLÓgICOS}

A investigação realizada teve um caráter crosssectional, com a aplicação de questionários uma única vez a cada respondente. Teve, ainda, um caráter descritivo voltado para apresentar as diversas características relativas à realidade investigada e, também, explicativa por ter buscado evidenciar os fatores implicados no fenômeno da mobilidade rotineira em pequenos municípios de economia agrícola (GIL, 2010, p.26). Empregou-se uma combinação de desenhos de pesquisa qualitativos e quantitativos para compreender este fenômeno. Conforme Reichardt; Cook (1979, p.14), a abordagem qualitativa busca descrever significados que são socialmente construídos e que assumem uma dimensão subjetiva. Enquanto a abordagem quantitativa, procura descrever os significados da realidade estudada de forma objetiva permitindo uma análise focalizada e pontual dos dados.

A coleta de dados foi realizada com a população rural do pequeno município de Araponga, pertencente à microrregião de Viçosa, Minas Gerais. Este local foi escolhido em virtude do município ter uma população inferior a 20.000 habitantes e ter uma economia agrícola, tal como acontece com mais de $80 \%$ dos municípios brasileiros (VEIGA, 2004, p.80). Adotou-se neste estudo uma amostra probabilística e representativa da população. Os indivíduos que a constituíram foram escolhidos por um processo em que todos os membros da população tinham a mesma probabilidade de fazer parte da amostra. Assim, a amostra representativa da população permitiu que os resultados fossem confiáveis para avaliar as características da população. Em uma primeira etapa, para o cálculo da amostra, identificou-se as unidades domiciliares rurais, através da consulta aos dados cadastrais fornecidos pelas Unidades Básicas de Saúde (UBS) da Secretaria de Saúde de Araponga, MG. 
O tamanho amostral foi definido segundo a fórmula da proporção finita de Bolfarine e Bussab (2005, p. 28), assumindo-se o erro de estimativa de $10 \%$ e $95 \%$ como grau de confiança. Assim, a amostra foi composta por 94 indivíduos. Os dados primários foram coletados por meio de um Survey com perguntas fechadas e abertas, sendo a unidade de análise o indivíduo, segmentado em faixas etárias e gênero. Adotou-se também, uma metodologia complementar do tipo observação participante realizada durante algumas viagens de ônibus acompanhando os deslocamentos realizados pelos rurais no seu dia a dia. Os dados do Survey foram tabulados e submetidos a análises estatísticas com a ajuda do software SPSS 20.0 (Statistical Package for Social Sciences).

Para a descrição e comparação dos dados, partiu-se de uma análise exploratória (EAD) utilizada sob a perspectiva de gênero e de diferenças geracionais. Para tanto dividiu-se os entrevistados em estratos, configurados a partir da faixa estaria na qual o indivíduo se incluía. As faixas etárias criadas seguiram uma lógica voltada para a cultura local, segundo a qual "jovens" seriam os indivíduos que ainda se dedicavam ao estudo e não se casaram, tendo geralmente entre os 15 e os 19 anos; os "jovens adultos" estavam na faixa dos 20 aos 29 anos, já tendo um percentual significativo de casados; na faixa dos 30 aos 39 anos, estavam aqueles indivíduos que possuíam filhos pequenos; na faixa etária dos 40 a 49 anos, aqueles indivíduos que já possuíam filhos adolescentes; na faixa etária dos 50 a 59 anos, aqueles que já possuíam filhos adultos e, na faixa etária acima dos 60 anos, aqueles indivíduos que já possuíam filhos morando fora de casa e que já recebiam ou estão prestes a receber aposentadoria. Excluiu-se dos extratos para os quais seriam aplicados os questionários, as faixas etárias os indivíduos com menos de 15 anos.

A fim de realizar análises sobre a dinâmica dos deslocamentos campo - cidade realizado pelos rurais, considerando a perspectiva de gênero e das diferenças geracionais, trabalhou-se com as seguintes variáveis: escolaridade, renda, frequência dos deslocamentos, destinos buscados, meios utilizados e o tempo gasto para se deslocar. Objetivando compreender as pequenas escalas dos fluxos cotidianos rurais, atentou-se a uma descrição pormenorizada das motivações que os direcionam para a cidade, bem como pelos espaços rurais. Assim, analisou-se, a mobilidade com a finalidade de estudar, trabalhar, consumir bens pessoais, domésticos e para a propriedade, a busca de serviços de saúde e bancários e para o lazer.

\section{A MOBILIDADE ROTINEIRA ENTRE O CAMPO E A CIDADE EM PEQUENOS MUNICÍPIOS}

Segundo os dados do Censo do IBGE, o município de Araponga apresentava em 2010 uma população (Tabela 4) de aproximadamente 8.152 habitantes: 3041 habitantes vivendo na cidade e 5.011 no campo, respectivamente, $37,3 \%$ e $62,7 \%$ da população. O município possui dimensão territorial de $303,8 \mathrm{Km}^{2}$ e densidade demográfica de 26,8hab./Km. A economia de Araponga é típica de muitos municípios brasileiros, sendo voltada para a prestação de serviços e atividades ligadas à agropecuária. A configuração agrária do município é composta por $85 \%$ de "pequenas propriedades", com menos do que 50 hectares. O município tem no café a principal fonte de renda das pessoas que residem no campo. 
Tabela 1 - População rural residente por faixa etária e sexo em Araponga

\begin{tabular}{cccc}
\hline Anos & População Urbana & População Rural & Total \\
\hline 1970 & $925(14,6 \%)$ & $5.429(85,4 \%)$ & 6.354 \\
1980 & $1.081(16,4 \%)$ & $5.488(83,6 \%)$ & 6.569 \\
1991 & $1.631(20,8 \%)$ & $6.243(79,2 \%)$ & 7.874 \\
2000 & $2.537(32,0 \%)$ & $5.374(68,0 \%)$ & 7.911 \\
2010 & $3.041(37,3 \%)$ & $5.111(62,7 \%)$ & 8.152 \\
$2012 *$ & - & - & 8.188 \\
\hline
\end{tabular}

Fonte: IBGE, Censo Demográfico 2010.

O Índice de Desenvolvimento Humano Municipal (IDHM) de Araponga era o segundo pior IDHM do Estado de Minas Gerais, dado revelado segundo o Programa das Nações Humanas para o Desenvolvimento. O IDHM é um relatório produzido a cada 10 anos e aborda como critério os dados relativos à expectativa de vida (longevidade), à renda e à educação da população. Este índice opera dentro de uma escala de 0 a 1 . Quanto mais próximo de 1 , maior o desenvolvimento humano. A educação, apesar de registrar avanços na última década, continua sendo o setor mais atrasado em Araponga, apresentando um IDHM na educação de 0,536, considerado como de baixo desenvolvimento humano. No que tange, à dinâmica populacional do município de Araponga, referente ao período compreendido entre a década de 1970 até o ano 2012, apresenta características convergentes com a de muitos outros municípios brasileiros com perfil agrícola, conforme pode ser observado na tabela 2 que se segue.

Tabela 2 - Evolução da população urbana e rural nos anos de 1970 a 2010 em números relativos e absolutos em Araponga, MG

\begin{tabular}{|c|c|c|c|c|c|c|c|c|c|c|}
\hline \multirow[t]{2}{*}{ Municípios } & \multicolumn{2}{|c|}{$\begin{array}{c}\text { População } \\
1970 \\
\end{array}$} & \multicolumn{2}{|c|}{$\begin{array}{c}\text { População } \\
1980\end{array}$} & \multicolumn{2}{|c|}{$\begin{array}{c}\text { População } \\
1991 \\
\end{array}$} & \multicolumn{2}{|c|}{$\begin{array}{l}\text { População } \\
2000\end{array}$} & \multicolumn{2}{|c|}{$\begin{array}{c}\text { População } \\
2010\end{array}$} \\
\hline & $\mathrm{R}^{*}$ & $\mathrm{U}^{* *}$ & $\mathrm{R}$ & $\mathrm{U}$ & $\mathrm{R}$ & $\mathrm{U}$ & $R$ & $U$ & $R$ & $U$ \\
\hline Alto Rio Doce & 80,8 & 19,2 & 77,8 & 22,2 & 72 & 28 & 64,6 & 35,4 & 58,3 & 41,7 \\
\hline Amparo do Serra & 82,1 & 17,9 & 75,4 & 24,6 & 64 & 35 & 54,2 & 45,8 & 47,8 & 52,2 \\
\hline Araponga & 84,8 & 15,2 & 83,4 & 16,6 & 79,2 & 20,8 & 68 & 32 & 62,7 & 37,3 \\
\hline Brás Pires & 86,9 & 13,1 & 84,7 & 15,3 & 76 & 24 & 64,7 & 35,3 & 52 & 48 \\
\hline Cajuri & 72 & 28 & 61,3 & 38,7 & 54 & 46 & 45,4 & 54,6 & 48,2 & 51,8 \\
\hline Canaã & 86,6 & 13,4 & 82,6 & 17,4 & 79,3 & 20,7 & 70,3 & 29,7 & 59,9 & 40,1 \\
\hline Cipotânea & 81 & 19 & 80,3 & 19,7 & 74 & 26 & 61,9 & 38,1 & 54 & 46 \\
\hline Coimbra & 65,3 & 34,7 & 54,4 & 45,6 & 46 & 54 & 46,6 & 53,4 & 30 & 73 \\
\hline Ervália & 75,1 & 24,9 & 73,7 & 26,3 & 67,7 & 32,3 & 55,6 & 44,4 & 47,2 & 52,8 \\
\hline Lamim & 83 & 17 & 77,4 & 22,6 & 71,3 & 28,7 & 62 & 38 & 56,2 & 43,8 \\
\hline Paula Cândido & 79,4 & 20,6 & 71,4 & 28,6 & 63,8 & 36,2 & 57 & 43 & 46,8 & 53,2 \\
\hline Pedra do Anta & 85,8 & 14,2 & 76,8 & 23,2 & 62,7 & 37,3 & 47 & 53 & 34,9 & 65,1 \\
\hline Piranga & 82 & 18 & 80,3 & 19,7 & 76,3 & 23,7 & 70,1 & 29,9 & 65,4 & 34,6 \\
\hline Porto Firme & 80,6 & 19,4 & 77 & 23 & 70,7 & 29,3 & 58,9 & 41,1 & 53,7 & 46,3 \\
\hline Presidente Bernardes & 90,9 & 9,1 & 87,9 & 12,1 & 84,6 & 15,4 & 76,7 & 23,3 & 70,3 & 29,7 \\
\hline Rio Espera & 76,6 & 23,4 & 73,6 & 26,4 & 73,2 & 26,8 & 67,8 & 32,2 & 60,4 & 39,6 \\
\hline São Miguel do Anta & 71,6 & 28,4 & 61,1 & 38,9 & 56 & 44 & 49,9 & 50,1 & 44,6 & 55,4 \\
\hline Senhora de Oliveira & 72 & 28 & 63,7 & 36,3 & 54,9 & 45,1 & 51,8 & 48,2 & 42,8 & 57,2 \\
\hline Teixeiras & 66,9 & 33,1 & 55,5 & 45,5 & 46,7 & 53,3 & 37,7 & 62,3 & 32,9 & 67,1 \\
\hline Viçosa & 33,9 & 66,1 & 19,4 & 80,6 & 10 & 90 & 7,9 & 92,1 & 6,9 & 93,1 \\
\hline
\end{tabular}

Fonte: IBGE, 2010. 
Como observado na tabela 2, a evolução da população urbana e rural ao longo das décadas mostra que este pequeno município de economia cafeeira vem mantendo um crescimento constante da sua população. Ainda que a população rural venha diminuindo, este processo vem se efetivando de forma lenta e apontando para uma dinâmica de deslocamento intra-municipal. A tabela 3 destaca a dinâmica populacional relativa ao campo e a cidade nos municípios da microrregião de Viçosa, ao longo das últimas cinco décadas, permitindo o enquadramento de Araponga dentro de um quadro mais amplo.

Tabela 3 - Dados percentuais da distribuição da população rural e urbana na Microrregião de Viçosa nas décadas 1970, 1980, 1991, 2000 e 2010

\begin{tabular}{ccccc}
\hline & PIB Agropecuário & PIB Industrial & PIB Serviços & PIB per capita \\
\hline Brasil & 196.100 .000 .000 & 983.400 .000 .000 & 2.561 .200 .000 & $22.402,00$ \\
Minas Gerais & 30.214 .659 & 103.353 .712 & 218.334 .160 & $20.324,58$ \\
Araponga & $\mathbf{2 5 . 0 1 2}$ & $\mathbf{5 . 2 2 1}$ & $\mathbf{3 2 . 1 7 7}$ & $\mathbf{7 . 7 7 9 , 9 7}$ \\
\hline
\end{tabular}

$* \mathrm{R}=$ população rural; $* * \mathrm{U}=$ população urbana

Fonte: IBGE, Censo Demográfico de 1970, 1980, 1991, 2000 e 2010.

Como observado na tabela 3, metade dos municípios da microrregião de Viçosa apresentavam, ainda em 2010, a predominância da população rural sobre a urbana e uma densidade demográfica inferior a 50 habitantes por $\mathrm{km}^{2}$. Tal fato permite assinalar que a ocupação territorial nestes pequenos municípios é desconcentrada favorecendo a manutenção de uma estrutura agrária calcada nos pequenos estabelecimentos rurais. Essas baixas densidades demográficas, como menciona Veiga (2004) permitem compreender que nestes municípios, o grau das modificações do meio natural vem sendo menor, um vez que, esta variável expressa a pressão antrópica sobre o espaço. Logo, nestes pequenos municípios, o modo de vida rural ainda é dominante. Já no que diz respeito às características da economia desta pequena cidade, esta apresenta-se fortemente ancorada na agricultura e no setor terciário, tal como o observado em tantas outras pequenas cidades brasileiras. A tabela 4, a seguir, apresenta estas características econômicas.

\section{Tabela 4 - Produto Interno Bruto (PIB) do Brasil, Minas Gerais e Araponga}

\begin{tabular}{cccc}
\hline $\begin{array}{c}\text { Faixas etárias } \\
\text { (Anos) }\end{array}$ & $\begin{array}{c}\text { Número e } \% \text { de } \\
\text { residentes }\end{array}$ & Sexo feminino & Sexo masculino \\
\hline 0 a 4 & $363(7,10 \%)$ & $181(3,54 \%)$ & $183(3,58 \%)$ \\
5 a 9 & $464(9,07 \%)$ & $248(4,85 \%)$ & $216(4,22 \%)$ \\
10 a 14 & $487(9,52 \%)$ & $201(3,93 \%)$ & $286(5,59 \%)$ \\
15 a 19 & $462(9,03 \%)$ & $226(4,42 \%)$ & $236(4,61 \%)$ \\
20 a 24 & $488(9,54 \%)$ & $224(4,38 \%)$ & $264(5,16 \%)$ \\
25 a 29 & $519(10,15 \%)$ & $230(4,50 \%)$ & $289(5,65 \%)$ \\
30 a 39 & $846(16,55 \%)$ & $396(7,74 \%)$ & $450(8,80 \%)$ \\
40 a 49 & $554(10,83 \%)$ & $249(4,87 \%)$ & $305(5,96 \%)$ \\
50 a 59 & $401(7,84 \%)$ & $221(4,32 \%)$ & $179(3,50 \%)$ \\
60 a 69 & $294(5,75 \%)$ & $160(3,13 \%)$ & $133(2,60 \%)$ \\
70 ou mais & $234(4,57 \%)$ & $102(1,99 \%)$ & $132(2,58 \%)$ \\
\hline TOTAL & $5.111(100 \%)$ & $2.437(47,68 \%)$ & $2.674(52,31 \%)$ \\
\hline
\end{tabular}

Fonte: IBGE, 2012. 
Para além dos dados apresentados na tabela 4, as pequenas cidades compartilham entre si outras características constitutivas do seu perfil socioeconômico, como questões relativas ao tipo de emprego, ao acesso à saúde e à escolaridade. Estas variáveis serão tratadas no presente estudo sob a ótica do deslocamento rotineiro entre o campo e a cidade entre as próprias localidades rurais, como será apresentado nas tabelas a seguir.

\section{Tabela 5 - Índice de Desenvolvimento Humano Municipal (IDHM) de Araponga}

\begin{tabular}{cc}
\hline \multicolumn{2}{c}{ Evolução do IDHM } \\
\hline 1991 & 0,277 \\
2000 & 0,393 \\
2010 & 0,536 \\
\hline
\end{tabular}

Fonte: PNUD, 2014.

No que diz respeito à mobilidade motivada para a finalidade de estudar, pesquisada nesta investigação, esta apresentou-se restrita aos jovens, embora mesmo entre eles tenha sido pouco frequente ${ }^{5}$. Observou que $65 \%$ dos rapazes e $75 \%$ das moças nunca se deslocavam para estudar. Entre os jovens que se deslocavam para estudar, a maior parte deslocava-se para escolas do próprio município. Entretanto, constatou-se também o vínculo com a Escola Família Agrícola, que funcionava sob regime de alternância, no qual os jovens passavam 15 dias internos na escola e 15 dias em atividades práticas desenvolvidas na própria propriedade. Para irem estudar, os rapazes utilizavam mais o transporte público do que as moças: $25 \%$ contra $12,5 \%$, respectivamente. Em relação ao tempo gasto para o deslocamento da residência até - local de estudo, a média de deslocamento dos rapazes foi de 18 minutos e das moças de 3,1 minutos, em virtude de elas estudarem mais perto de onde moravam. Miranda e Domingues (2010, p.63), em seus estudos sobre os efeitos da composição do domicílio nas escolhas dos deslocamentos rotineiros, também encontraram resultados para o tempo de deslocamento das mulheres sendo menores que a média dos homens.

Já no que diz respeito ao deslocamento para trabalhar constatou-se, também, que este estava circunscrito, majoritariamente, dentro da própria comunidade rural na qual os respondentes residiam. Observou-se que os rapazes se deslocavam mais que as moças: $45 \%$ contra $19 \%$. Em relação aos adultos a situação se inverteu: os homens adultos se deslocavam menos do que as mulheres para trabalharem na própria comunidade: $26 \%$ contra $36 \%$, respectivamente. Já entre os idosos, tanto os homens quanto as mulheres não saíam mais do espaço de origem para exercerem atividades laborais. Quanto aos meios de locomoção utilizados para trabalhar (Tabela 6), a moto se constituía no meio de transporte mais utilizado pelos habitantes do campo, por permitir um deslocamento flexível e veloz em comparação aos demais meios. Entretanto, observou-se um forte viés de gênero no uso dos meios de transporte. Os homens eram os seus maiores utilizadores, enquanto as mulheres adultas eram usuárias de meios de transporte não automotores ${ }^{6}$. Talvez, em função disto, as mulheres deslocavam-se mais para curtas distâncias. Logo o tempo de deslocamento mostrou-se inferior ao dos homens.

\footnotetext{
5 Foi mencionado por um respondente adulto do sexo masculino o deslocamento para realização de qualificação contínua através da participação em cursos e eventos sobre medicina alternativa, com frequência mensal.

6 A categoria analítica "meios de transporte não automotores" refere-se aos meios de transporte: charrete; carroça, carro de boi, bicicleta, andar a pé e a cavalo.
} 


\section{Tabela 6 - Meio de transporte utilizado para trabalhar}

\begin{tabular}{lrrrr}
\hline & \multicolumn{3}{c}{ Respondentes por geração e sexo } \\
\cline { 2 - 5 } & \multicolumn{3}{c}{ Jovens } & \multicolumn{2}{c}{ Adultos } \\
\cline { 2 - 5 } Não se aplica & $\mathrm{M}^{*}$ & $\mathrm{~F} *$ & $\mathrm{~F}$ \\
\cline { 2 - 5 } Carro próprio & 15,0 & 50,0 & 47,8 & 45,5 \\
Moto própria & & & 4,3 & \\
Meios de transporte não automotores & 65,0 & 25,0 & 26,1 & 18,2 \\
Trator & 20,0 & 18,8 & 21,7 & 36,4 \\
\hline
\end{tabular}

$\mathrm{M}^{*}=$ sexo masculino; $\mathrm{F}^{* *}=$ sexo feminino.

Fonte: Inquérito por questionário semi-estruturado, realizado no município de Araponga, MG, de Julho a Setembro de 2014.

No que tange ao tempo gasto para se deslocar até ao trabalho, os rapazes gastavam, em média, mais tempo do que as moças, fato compreensível já que eram eles que mais se deslocavam para trabalhar fora da comunidade: 15,5 minutos contra 13,4 minutos $^{7}$. Para Souza (2011, p.15), o tempo de deslocamento entre as mulheres passa a ser mediado pelo tipo de relação com o mercado de trabalho, ou seja, mulheres que trabalham fora de casa efetuam mais deslocamentos do que as donas de casa ou as que realizam trabalho remunerado dentro de casa. Logo, as mulheres que trabalham apenas no próprio domicílio, de forma remunerada ou não, apresentam um menor número de deslocamentos do que o dos homens. Para Pereira; Schwanen (2013, p.23), mesmo considerando a maior inserção da mulher no mercado de trabaIho nas últimas décadas, os dados de usos do tempo para trabalhar, mostram que há uma diferença significativa no tempo dedicado a esses movimentos por homens e mulheres. Portanto, as mulheres apresentam um raio espacial restrito apresentando deslocamentos de curta duração.

Segundo Souza (2011, p.16), a natureza dos deslocamentos das mulheres adultas se relacionaria a busca por compatibilizar o seu tempo com o do grupo familiar, o que implicaria em deslocamentos voltados para os cuidados com a família, para a realização de compras e busca serviços. Também Souza (2011, p.14) aponta que a percepção da mulher sobre a vida cotidiana assenta-se em padrões mais distributivos, voltados para o grupo familiar do que os do homem. Para Pereira; Schwanen (2013, p.26), o gênero é determinante da intensidade, do tempo médio e do tipo de transportes que se utiliza nos deslocamentos. Em relação aos respondentes adultos, observou-se que os homens eram aqueles que gastavam em média, menos tempo para se deslocar, enquanto as mulheres adultas eram as que gastavam mais tempo para se deslocarem. A posse e o uso preferencial da moto e do carro por parte dos homens pode constituir em um fator explicativo deste fato. Ravenstein (1980, p.44) um dos pioneiros a formalizar teorias acerca dos movimentos populacionais considerou que fatores como "distância" e "sexo" diferenciavam os deslocamentos. As mulheres tenderiam a realizar movimentos de curta distância, enquanto os movimentos de longa distância estariam em sua maioria associados aos homens.

Os dados relativos ao trabalho e à escolaridade indicaram, portanto, que neste pequeno município de economia agrícola, preponderava a maior valorização do tra-

\footnotetext{
7 Os valores de desvio padrão entre os jovens do sexo masculino foram inferiores à média revelando que estão concentrados em torno do tempo médio. Já entre as jovens o desvio padrão apresentou-se superior aos valores de tempo médio, demonstrando que os tempos gastos estão dispersos em torno da média.
} 
balho em detrimento do estudo, um traço típico de um modo de vida rural tradicional". Constatou-se, ainda, que o deslocamento para trabalhar e estudar apresentaram-se restritos à localidade de origem dos entrevistados, o que evidencia que a economia cafeeira alimenta um ciclo de base local. Para Milbourne (2014, p.332) e Ingold (2011, p.148), a mobilidade rural se daria votada para as necessidades da vida diária dos indivíduos, principalmente, no que se refere ao trabalho e no lazer. Segundo Milbourne (2007, p.385), no contexto de uma comunidade ruralizada, a condição de vida voltada para a auto sustentação e o sentimento de pertencimento influenciariam na amarração espacial. Na pesquisa realizada no município de Araponga, observou-se que o acesso aos meios de transporte não foi utilizado pela grande maioria da população para buscar trabalho e estudo fora do lugar de origem. Tal situação pode estar ligada ao fato de a economia agrícola do município, baseada na cultura do café, estar gerando condições suficientes para os indivíduos concretizarem os seus projetos de vida em nível local.

Neste sentido, o rendimento mensal domiciliar pode permitir um melhor enquadramento da situação. Como destacou Goodwin-Hawkins (2015, p.168), a monetarização da vida amplia as possibilidades de mobilidade dos indivíduos. No presente estudo observou-se que nas famílias dos entrevistados mais jovens, como também nas dos entrevistados adultos, a renda mensal da família (Tabela 7) encontrava-se próxima a um salário mínimo e meio $(R \$ 1100,00)$. Os maiores ganhos foram encontrados nas famílias com idosos do sexo masculino, nas quais o rendimento médio mensal ainda foi superior ao das famílias com idosas: $R \$ 2675,00$ contra $R \$$ 1432,00 , respectivamente. Conforme o IBGE (2010), o rendimento domiciliar per capita médio do brasileiro em 2014 foi de R\$1.052,00. Sendo assim, os rendimentos encontrados nesta localidade rural estavam próximos à média nacional. Segundo Camarano (2002, p.16), o incremento da renda rural estaria associado ao envelhecimento populacional. Para tal autora, o impacto do benefício da seguridade social na renda das famílias rurais estaria influenciando na melhoria generalizada da qualidade de vida nas sociedades rurais. De acordo com Rambaud (1973, p.69), a monetarização da economia rural, levaria ao processual aprofundamento do modo de vida urbano no campo. Os modos de vidas pautados pelos desafios imediatos da subsistência iriam aos poucos sendo substituídos pela mediação do dinheiro voltado para a aquisição de alimentos, de bens e serviços. Tais processos se concretizariam mediante o deslocamento rotineiro entre o campo e a cidade.

Tabela 7 - Rendimento mensal familiar

\begin{tabular}{ccccccc}
\hline Respondente & Sexo & Frequência & Mínimo & Máximo & Média & S* \\
\hline \multirow{2}{*}{ Jovem } & Masculino & 20 & 350 & 2500 & 1031,0 & 613,8 \\
& Feminino & 16 & 200 & 3000 & 1168,8 & 781,6 \\
\cline { 2 - 7 } Adulto & Masculino & 23 & 250 & 7500 & 1158,7 & 1495,9 \\
& Feminino & 22 & 300 & 2500 & 1034,1 & 699,7 \\
\cline { 2 - 7 } Idoso & Masculino & 6 & 1450 & 4000 & 2675,0 & 1022,6 \\
& Feminino & 7 & 724 & 2000 & 1432,0 & 371,9 \\
\hline
\end{tabular}

*S = valor referente ao desvio padrão.

Fonte: Inquérito por questionário semi-estruturado, realizado no município de Araponga, MG, de Julho a Setembro de 2014.

No estudo de Candido (1997, p.207) a respeito das mudanças nos modos de vida do caipira paulista já na década de 50, o autor chamou a atenção para as consequências da substituição da racionalidade voltada para a autoprodução em nível doméstico para a racionalidade voltada para a compra de bens de consumo. A 
monetarização da vida, para o autor, introduzia o caipira paulista na lógica da sociedade de consumo. No que se refere à pesquisa realizada em Araponga, observou-se que o deslocamento para o consumo, voltado para a aquisição de produtos para uso pessoal, como roupas e calçados, se constituía em uma realidade entre todas as gerações dos respondentes e apresentava uma clara tendência de gênero. Em termos do consumo mais assíduo (uma vez por mês) observou-se que as mulheres idosas, que recebiam aposentadoria, eram aquelas que mais se deslocavam para comprar bens de uso pessoal: $43 \%$ do consumo mensal era realizado por elas. Entre os que menos se deslocavam com fins de consumo pessoal, destacavam-se os idosos do sexo masculino: $50 \%$ deles nunca se deslocava para consumir itens de uso pessoal.

Notou-se, portanto, um claro recorte de gênero nas práticas de relativas ao consumo pessoal por parte dos homens e das mulheres idosas. Tais deslocamentos para o consumo de bens para uso pessoal evidencia a importância dos pequenos municípios como suporte para o consumo daqueles que vivem no campo. Ingold (2011, p.160) e Heley; Jones (2012, p.210) ressaltam que a mobilidade dos rurais abre lugar à ampliação da experiência contextual e processual. Esta visão reconhece que as pessoas não vivem fechadas em limites geográficos, mas interagindo de forma dinâmica com o mundo e com as pessoas no seu entorno.

Para Milbourne (2014, p.327), especial atenção deve ser dada aos estudos da mobilidade no contexto dos espaços rurais. Na presente pesquisa para além do deslocamento para fazer compras pessoais destacou-se o deslocamento realizado para fazer compras para a casa, como compras de alimentos e de produtos de limpeza (Tabela 8). Os homens, adultos e idosos, foram aqueles que mais se deslocavam para fazer compras para a manutenção da casa. (ZANON, 2013, p.57). O fato de socialmente o homem ter a imagem de provedor da casa, dá sentido aos elevados percentuais relacionados com as compras realizadas por eles.

\section{Tabela 8 - Frequência do deslocamento para compras de uso doméstico}

\begin{tabular}{ccccccc}
\hline & \multicolumn{3}{c}{ Respondentes por geração e sexo } \\
\cline { 2 - 7 } No) & \multicolumn{2}{c}{ Jovens } & \multicolumn{3}{c}{ Adultos } & \multicolumn{1}{c}{ Idosos } \\
\cline { 2 - 7 } Nunca & $\mathrm{M}$ & $\mathrm{F}$ & $\mathrm{M}$ & $\mathrm{F}$ & $\mathrm{M}$ & $\mathrm{F}$ \\
\cline { 2 - 7 } & 50,0 & 62,5 & 8,7 & 45,5 & 16,7 & 28,6 \\
Mais de 1x/semana & & & & & 14,3 \\
Uma x/mês & 25,0 & 25,0 & 56,5 & 45,5 & 16,7 & 42,9 \\
Mais de 1x/mês & 20,0 & 12,5 & 34,8 & 9,1 & 66,7 & 14,3 \\
Algumas x/ano & 5,0 & & & & & \\
\hline
\end{tabular}

Fonte: Inquérito por questionário semi-estruturado, realizado no município de Araponga, MG, de Julho a Setembro de 2014.

Estas compras eram realizadas através de deslocamentos realizados de forma diferenciada por homens e mulheres. Entre os homens adultos, o tempo médio de deslocamento para a realização de compras para a casa foi de 29 minutos contra 19 minutos das mulheres. Este fato pode estar associado às mulheres fazerem compras no próprio distrito do município, enquanto os homens se deslocavam para o centro urbano do próprio município. Observou-se, assim, que o comércio do próprio município supria as principais demandas dos moradores do campo (Tabela 9). Fica evidente, portanto, a importância dos pequenos municípios que se configuram como centralidades regionais, como aponta CORRÊA $(2011$, p.6) dando suporte para o comércio de uso pessoal daqueles que vivem no campo. 


\section{Tabela 9 - Destino do deslocamento para compras de uso doméstico}

\begin{tabular}{|c|c|c|c|c|c|c|}
\hline \multirow{3}{*}{$(\%)$} & \multicolumn{6}{|c|}{ Respondentes por geração e sexo } \\
\hline & \multicolumn{2}{|c|}{ Jovens } & \multicolumn{2}{|c|}{ Adultos } & \multicolumn{2}{|c|}{ Idosos } \\
\hline & $M$ & $\mathrm{~F}$ & M & $\mathrm{F}$ & $\mathrm{M}$ & $\mathrm{F}$ \\
\hline Não se aplica & 50,0 & 62,5 & 8,7 & 45,5 & 16,7 & 28,6 \\
\hline Para o distrito do próprio município & 10,0 & 18,8 & 17,4 & 22,7 & 33,3 & 14,3 \\
\hline Para o centro urbano do próprio município & 15,0 & 6,3 & 30,4 & 4,5 & 50,0 & 42,9 \\
\hline Para outro pequeno município vizinho & 5,0 & 6,3 & 21,7 & 4,5 & & 14,3 \\
\hline Para a própria comunidade & 10,0 & 6,3 & 13,0 & 9,1 & & \\
\hline Para outra comunidade rural do próprio município & 5,0 & & 4,3 & 13,6 & & \\
\hline Para a própria comunidade e para outro pequeno município vizinho & 5,0 & & 4,3 & & & \\
\hline
\end{tabular}

Fonte: Inquérito por questionário semi-estruturado, realizado no município de

Araponga, MG, de Julho a Setembro de 2014.

No que diz respeito ao deslocamento para a realização de compras para a propriedade tais como insumos agrícolas e equipamentos, este configurou-se como predominantemente masculino: $78,3 \%$ (adultos) e 33,3\% (idosos). Quanto ao local de realização das compras para a propriedade mais uma vez evidenciou-se as compras realizadas dentro do próprio município. Todavia, $34,8 \%$ dos adultos homens compravam também em pequenos municípios vizinhos.

Quanto à busca por serviços de saúde como a ida em médicos e/ou dentistas notou-se, também, um padrão genderizado: as mulheres se deslocavam muito mais do que os homens, com exceção dos idosos, estrato no qual os Senhores se deslocavam mais em busca de atendimento médico do que as Senhoras. No entanto, entre os jovens observou-se que, $100 \%$ das moças se deslocavam com esta finalidade contra $60 \%$ dos rapazes. Entre os adultos estas porcentagens eram de $91 \%$ de deslocamento das mulheres contra $48 \%$ dos homens. Já entre os idosos, $71,4 \%$ das Senhoras buscavam os serviços de saúde contra $83 \%$ dos Senhores. O município de residência foi o local com maior demanda para a prestação dos serviços relacionados à saúde, com exceção dos homens idosos, que necessitavam buscar serviços mais especializados na cidade polo da região ou mesmo na capital do Estado (Belo Horizonte). Diferentemente destes, as mulheres idosas tinham as suas demandas atendidas nas unidades básicas de saúde da comunidade rural, os quais eram complementados com idas esporádicas ao centro urbano do próprio município, bem como na cidade polo da microrregião. Desta forma percebeu-se que as mulheres se deslocavam com maior regularidade e proximidade, enquanto os homens de forma irregular e com necessidade de deslocamento para centros mais especializados.

Outro aspecto que se torna visível no que diz respeito à monetarização da vida no campo é o deslocamento para a realização de serviços bancários. Este tipo de deslocamento teve uma predominância mensal, estando vinculado ao centro urbano do próprio município. O pequeno município em estudo, Araponga, contava, com quatro agências funcionando no formato de posto avançado, via Correios ou via lotérica. Lidar com dinheiro, para os rurais entrevistados, mostrou-se uma atribuição em que os idosos se destacavam (Tabela 10). 
Tabela 10 - Frequência do deslocamento para realizar serviços bancários

\begin{tabular}{|c|c|c|c|c|c|c|}
\hline \multirow{3}{*}{$(\%)$} & \multicolumn{6}{|c|}{ Respondentes por geração e sexo } \\
\hline & \multicolumn{2}{|c|}{ Jovens } & \multicolumn{2}{|c|}{ Adultos } & \multicolumn{2}{|c|}{ Idosos } \\
\hline & M & $\mathrm{F}$ & M & $\mathrm{F}$ & M & $\mathrm{F}$ \\
\hline Nunca & 50 & 75 & 30,4 & 36,4 & & 14,3 \\
\hline Uma $1 x /$ mês & 35 & 18,8 & 43,5 & 63,6 & 66,7 & 85,7 \\
\hline Mais de $1 \mathrm{x} / \mathrm{mês}$ & 5 & & 4,3 & & 16,7 & \\
\hline Algumas $x$ /ano & 10 & 6,3 & 21,7 & & 16,7 & \\
\hline
\end{tabular}

Fonte: Inquérito por questionário semi-estruturado, realizado no município de Araponga, MG, de Julho a Setembro de 2014.

Em relação ao deslocamento dos rurais para a realização de atividades de lazer, como a ida a bares, a "vendas/botecos" e a festas, estas evidenciavam um claro recorte de gênero: as porcentagens de mulheres que nunca se deslocavam para uma atividade de lazer foram majoritárias em todas as gerações, enquanto entre os homens esta prática revelou uma regularidade de curto espaçamento. Ou seja, os homens se deslocavam à miúde para se divertir (Tabela 11). Todavia, para além das questões de gênero, vale à pena pontuar o significado do lazer. Rambaud (1973, p.147) mostrou que o lazer na França dos anos pós-Segunda Guerra era uma prática própria da "Cultura Urbana", que se expandiu da cidade para o campo, em função de ter sido na cidade que o tempo do não trabalho se demarcou mais precocemente em detrimento do campo, onde o trabalho era realizado de forma contínua, sem demarcações para o descanso.

\section{Tabela 11 - Prática do deslocamento para o lazer, segundo o sexo e faixas geracionais}

\begin{tabular}{|c|c|c|c|c|c|c|}
\hline \multirow{3}{*}{$(\%)$} & \multicolumn{6}{|c|}{ Respondentes por geração e sexo } \\
\hline & \multicolumn{2}{|c|}{ Jovens } & \multicolumn{2}{|c|}{ Adultos } & \multicolumn{2}{|c|}{ Idosos } \\
\hline & $\mathrm{M}$ & $\mathrm{F}$ & M & $\mathrm{F}$ & M & $\mathrm{F}$ \\
\hline Nunca & 5,0 & 25,0 & 43,5 & 54,5 & 16,7 & 85,7 \\
\hline Uma $x /$ semana & 45,0 & 12,5 & 13,0 & 13,6 & & \\
\hline Mais de $1 x /$ semana & 20,0 & 6,3 & 30,4 & 13,6 & 33,3 & \\
\hline Diariamente & 15,0 & & 4,3 & & & \\
\hline Uma x/mês & 5,0 & 31,3 & 4,3 & & 50,0 & 14,3 \\
\hline Mais de $1 \mathrm{x} / \mathrm{mês}$ & 10,0 & 6,3 & 4,3 & 4,5 & & \\
\hline Algumas vezes/ano & & 18,8 & & 13,6 & & \\
\hline
\end{tabular}

Fonte: Inquérito por questionário semi-estruturado, realizado no município de Araponga, MG, de Julho a Setembro de 2014.

Quanto aos espaços de lazer buscados pelos homens estes se situavam na própria comunidade, enquanto que as moças buscavam o centro urbano. Stropasolas (2006, p.214) mostrou, no seu estudo no Sul do Brasil, que as moças daquela região não queriam casar-se com rapazes que viviam no campo, em função de não desejarem reproduzir a sina das mães. Talvez este fato explique o maior deslocamento das moças para a cidade, quando comparado com os rapazes. Por fim, ao se observar o uso dos meios de transporte no campo, no município de Araponga, percebeu-se uma disseminação hierarquizada da moto entre homens e mulheres. Ainda que o percentual dos homens que usavam moto tenha sido praticamente o dobro quando comparado com o de mulheres, também entre elas a moto apareceu como o meio de transporte 
mais utilizado para se deslocar da localidade de origem. A exceção ficou por conta das idosas que se deslocavam mais de carro, ônibus ou charrete, não utilizando a moto. Já o ônibus se mostrou como um meio de transporte basicamente feminino, sendo que os homens praticamente não o utilizavam para se deslocar. Tal fato aponta para diferentes características do deslocamento realizado por homens e mulheres que vivem em localidades rurais. Elas se deslocavam com menor flexibilidade que eles, em virtude de utilizarem mais o ônibus e a charrete. Assim, os deslocamentos das mulheres eram mais demorados do que o dos homens. Entre estes, a categoria que apresentou maiores possibilidade de deslocamento flexível foram os idosos. Eles se deslocavam utilizando sempre carro ou moto, como pode ser observado na tabela 12 .

\section{Tabela 12 - Meio de transporte mais utilizado pelo respondente}

\begin{tabular}{lcccccr}
\hline & \multicolumn{6}{c}{ Respondentes por geração e sexo } \\
\cline { 2 - 7 } & \multicolumn{2}{c}{ Jovens } & \multicolumn{3}{c}{ Adultos } & \multicolumn{3}{c}{ Idosos } \\
\cline { 2 - 7 } & $\mathrm{M}$ & $\mathrm{F}$ & $\mathrm{M}$ & $\mathrm{F}$ & $\mathrm{M}$ & $\mathrm{F}$ \\
\cline { 2 - 7 } Carro & & 12,5 & 17,4 & 4,5 & 33,3 & 42,9 \\
Moto & 95 & 43,8 & 65,2 & 31,8 & 50 & \\
Ônibus & 5 & 25 & & 45,5 & & 28,6 \\
Meios de transporte & & 18,8 & 17,4 & 18,2 & & 14,3 \\
não automotores & & & & & 16,7 & 14,3 \\
Carro pago & & & & & \\
\hline
\end{tabular}

Fonte: Inquérito por questionário semi-estruturado, realizado no município de Araponga, MG, de Julho a Setembro de 2014.

Os dados relativos aos meios de transporte utilizados pelos rurais para se deslocarem evidencia o crescente entrelaçamento entre o campo e a cidade, ocasionando a aproximação do modo de vida rural em relação ao urbano, em termos, sobretudo, dos modos de morar, como mostram os estudos de Guimarães (2013, p. 164), Barros (2014, p. 108), Gomes (2014, p.113), Braga (2015, p.66), Nascimento (2013, p.48). Segundo Milbourne (2014, p. 331) as "rotas" dos rurais estão ligadas a processos envolvidos pela primazia de movimentos econômicos. De fato, os hábitos de consumo parecem ser a dimensão da cultura urbana que mais se adentra no campo. Os deslocamentos motivados para receber a aposentadoria e outros benefícios, em concomitância com os deslocamentos voltados para o consumo de bens duráveis e não duráveis foram mais expressivos que os deslocamentos realizados para estudar, trabalhar ou mesmo buscar serviços de saúde. Observou-se, ainda, que os deslocamentos dos habitantes do campo se efetivavam, sobretudo, circunscrito ao âmbito do próprio pequeno município e de outros pequenos municípios circunvizinhos. Esta dinâmica aponta para o fato de que os pequenos municípios se constituem em localidades centrais para os habitantes do campo. Tal evidência está muito vinculada a importância do comércio em nível local na consolidação de hábitos típicos da cultura urbana, como também apontou (MILBOURNE, 2014, p. 328).

Outra peculiaridade referente a dinâmica de deslocamento deste pequeno município que é importante de ser destaca, diz respeito a própria configuração do terreno. Trata-se de um município localizado em uma região montanhosa, cujo terreno acidentado poderia atuar como um fator continuamente limitante às possibilidades de deslocamento dos habitantes do campo, em decorrência de nele predominar as áreas serranas com longas declividades. Assim, também é importante considerar, que com a melhoria das estradas que tem um papel significativo ao conectar as 
pessoas entre si e com outros lugares e funcionamento em larga escala dos meios de transporte houve vantagens para o deslocamento campo-cidade. A estrada juntamente com os meios de transporte e comunicação tem levado as pessoas, produtos e ideias a sofrerem constantes mudanças.

As problemáticas das mobilidades rotineiras campo-cidade oferecem, assim, novas perspectivas sobre a complexa interação entre as porções espaciais, campocidade. Pode-se concluir que as diferenças entre o modo de vida no campo e na cidade vem se atenuando, sendo o deslocamento campo-cidade um instrumento para efetivação desta proximidade. Portanto, os estudos sobre a mobilidade rotineira campo-cidade podem trazer importantes contribuições para os debates em curso sobre a dinâmica dos pequenos municípios na contemporaneidade.

\section{CONSIDERAÇÕES FINAIS}

A intenção deste artigo foi a de compreender as mobilidades rotineiras das pessoas que vivem no campo em um pequeno município de economia agrícola, caso típico de mais de $80 \%$ dos municípios brasileiros. Analisou-se, assim, a intensidade e a finalidade dos fluxos rotineiros dos rurais para a cidade, de uma perspectiva de gênero e geração, conforme faixa etárias. Constatou-se, na pesquisa, que a renda advinda da economia cafeeira se constituía em um fator relevante para a permanência de traços típicos da cultura rural, como a persistência do trabalho manual na agricultura, o qual não exige escolaridade, mesclados a traços típicos da cultura urbana, como o consumo de bens, tecnologias e serviços, efetivados através do deslocamento rotineiro da "roça" para a "rua" ou para "cidades" da redondeza. A monetarização advinda tanto da remuneração relativa ao trabalho agrícola, como do não-agrícola, assim como da aposentadoria, pensão entre outras fontes de renda, tornou-se evidente como combustível para alimentar o uso dos rurais dos meios de transporte locomotores, como a moto, o carro e o ônibus. A constância no deslocamento entre o "campo" e a "cidade" influenciaram diretamente na flexibilização das fronteiras entre estas porções espaciais na vida dos rurais. Talvez, esta economia cafeeira, geradora de emprego e renda, sazonal, mas regular em sua oferta anual, bem como a renda advinda da aposentadoria e dos programas sociais do governo, como o bolsa família, possam ajudar a explicar o fato deste pequeno município de economia cafeeira apresentar um crescimento pequeno, mas contínuo, da sua população ao longo das últimas três décadas. Tal crescimento parece estar sustentado na relativa satisfação por parte dos rurais acerca das suas necessidades de consumo, assim como pela relativa satisfação encontrada no acesso a serviços de saúde, educação e lazer, encontrados em âmbito local e regional.

Observou-se neste estudo, ainda, que a mobilidade dos rurais apresentou peculiaridades quanto ao gênero, mas não entre as faixas geracionais. Os homens foram os habitantes do campo que mais se deslocavam buscando o centro urbano do município e outros pequenos municípios vizinhos. Isto em função deles possuírem os meios de transporte e renda numericamente superior as das mulheres, mas, também, por ser socialmente mais associado a eles a prática do deslocamento. Já as mulheres apresentaram o deslocamento circunscrito ao distrito do município, tendo ficado evidente a dependência das mesmas de meios de transporte não próprios e não automotores.

Embora este trabalho, não tenha tratado a mobilidade como uma variável causal em relação às mudanças dos modos de vida das famílias que vivem no campo, 
percebeu-se que esse movimento tem sido um importante indicador das dimensões em que o modo de vida rural vem se modificando. Portanto, os resultados mostraram que a mobilidade rural em pequenos municípios reflete o potencial, a centralidade e a continuidade dos fluxos vividos de mudança rural, sobretudo, no seu modo de morar e nos seus hábitos de vida. Contudo, há muito ainda por se explorar frente os ritmos da vida cotidiana rural que de nada são discretos, mas flexíveis e interconectados e que juntos constituem uma realidade rural que longe de ser fixa, está em pleno movimento.

\section{REFERÊNCIAS}

BARROS, V. A. M. A aposentadoria rural e as mudanças nos modos de vida dos idosos que vivem no campo: em análise os municípios de Piranga e São Miguel do Anta, Minas Gerais. 2014. 150f. Dissertação (Mestrado em Extensão Rural) - Programa de Pós Graduação em Extensão Rural, Universidade Federal de Viçosa, Viçosa. 2014.

BECKER, O. M. S. Mobilidade espacial da população: conceitos, tipologia, contextos. In: CASTRO, I. E; GOMES; P. C. C; CORRÊA, R. L (Org.). Explorações Geográficas. Rio de Janeiro: Bertrand Brasil, 1997. 367p.

BELL, M. OSTI, G. Mobilities and ruralities: an introduction. Sociologia Ruralis, Oxford, v. 50, n. 3, p. 199-204. 2010. Disponível em: <http://onlinelibrary.wiley.com/doi/ 10.1111/j.1467-9523.2010.00518.x/pdf>. Acesso em: 08 ago. 2015.

BOLFARINE, H.; BUSSAB, W.O. Elementos de Amostragem. São Paulo: Edgar Blucher, 2005. 274p.

BRAGA, G. B.; FIUZA, A. L. C.; PINTO, N. M. A. Padrões de Consumo no Campo: O Modo de Vida dos Rurais Brasileiros. Revista de Extensão e Estudos Rurais, Viçosa, v. 4, n.1, p. 56-73, jan./jun. 2015. Disponível em: <http://www.revistarever.ufv.br/ index.php/rever/article/view/50/42>. Acesso em: 28 ago. 2015.

CAMARANO, A. A. Brazilian population ageing: differences in well-being by rural and urban areas. Rio de Janeiro: IPEA, 2002. p.1-27.

CANDIDO, A. Os parceiros do Rio Bonito: estudo sobre o caipira paulista e a transformação dos seus modos de vida. São Paulo: Ed 34. 8a ed. 1997. 376p.

CORRÊA, R. L. Interações espaciais. In: CASTRO, I. E. de; GOMES, P. C. da C.; CORRÊA, R. L. (Org.). Explorações geográficas: percursos no fim do século. Rio de Janeiro: Bertrand Brasil, 1997. p. 279-318.

As pequenas cidades na confluência do urbano e do rural. Geousp, São Paulo, n. 30, p. 5-12, 2011. Disponível em: <http://citrus.uspnet.usp.br/geousp/ ojs2.2.4/index.php/geousp/article/view/449/261>. Acesso em: 14 mai. 2015.

CRESSWELL, T; MERRIMAN, P. Geographies of Mobilities: Practices, Spaces, Subjects, Farnham: Ashgate, 2011. 276p.

GIL, A. C. Como elaborar projetos de pesquisa. São Paulo: Atlas, 2010.159 p. GOMES, N.F.M. A mobilidade socioespacial dos rurais e suas expressões citadinas: uma análise do município de Araponga, Minas Gerais. 2015. 189f. Dissertação (Mestrado em Extensão Rural) - Programa de Pós Graduação em Extensão Rural, Universidade Federal de Viçosa. 
GOODWIN-HAWKINS, B. Mobilities and the English Village: Moving Beyond Fixity in Rural West Yorkshire. Sociologia Ruralis, Oxforf, v. 55, n.2, p. 167-181, abril. 2015. Disponível em: <http://www.readcube.com/articles 10.1111\%2Fsoru.12043?r3 _referer =wol\&tracking_action =preview_click\&show_checkout $=1 \&$ purchase_ referrer=onlinelibrary.wiley.com\&purchase_site_license=LICENSE_DENIED >. Acesso em: 07 ago. 2015.

GUimARÃES, E. P; PINTO, N. M. A.; FIUZA, A. L. C. Os reflexos da urbanização do campo nos modos de moradia das famílias residentes na zona rural do município de Araponga - MG. Oikos: Revista Brasileira de Economia Doméstica, Viçosa, v. 24, n.2, p. 163-184. 2013. Disponível em: <http://www.seer.ufv.br/seer/oikos/index.php/ httpwwwseerufvbrseeroikos/article/view/141/177>. Acesso em: 20 set. 2014.

HELEY, J; JONES, L. Relational rurals: some thoughts on relating things and theory in rural studies. Journal of Rural Studies, v.28, n.3, p. 208-217, jul. 2012. Disponível em: < http://www.sciencedirect.com/science/article/pii/S0743016712000125>. Acesso em: 23 set. 2015.

INGOLD, T. Being alive: essays on movement, knowledge and description. London: Routledge, 2011. 270p.

MARX, K. O capital: crítica da economia política. Vol. III, Livro Terceiro. O Processo Global da Produção Capitalista, Tomo 1. São Paulo: Abril Cultural, 1984. p. 759-890.

MATOS, R. Geografia da população. Belo Horizonte: Editora UFMG, 2011. 164 p.

MERRIMAN, P. Mobility, Space and Culture. London: Routledge, 2012. 214p.

MILBOURNE, P. Re-populating rural studies: Migrations, movements and mobilities. Journal of Rural Studies, v. 23, n.3, p. 381-386, jul. 2007. Disponível em: < http:/ /www.sciencedirect.com/science/article/pii/S0743016707000289>. Acesso em: 17 nov. 2015.

Kitchen, L. Rural mobilities: Connecting movement and fixity in rural places. Journal of Rural Studies, v. 34, p. 326-336, abr. 2014. Disponível em: < <http:// ac.els-cdn.com/S0743016714000175/1-s2.0-S0743016714000175 main.pdf?_tid=7438df78-cc42-11e5-bc80>00000aacb360\&acdnat $=1454702329$ 0d0fb9cb3dda14565c352573fa59c9ce>. Acesso em: 18 nov. 2015.

MIRANDA, R. A.; DOMINGUES, E. P. Commuting to work and residential choices in Belo Horizonte. Urban Public Economics Review, Santiago de Compostela, n. 12, p. 41-71, 2010. Disponível em: <http://www.redalyc.org/pdf/504/50414006002.pdf>. Acesso em: 27 nov. 2015.

NASCIMENTO, P. F. A nova dinâmica campo-cidade revelada pelo turismo rural: o caso de Venda Nova do Imigrante - ES. CAMPO-TERRITÓRIO: revista de geografia agrária, Uberlândia, v. 8, n. 15, p. 1-21, fev. 2013. Disponível em:< http:// www.seer.ufu.br/index.php/campoterritorio/article/viewFile/22082/12070>. Acesso em: 16 abr. 2013.

PEREIRA, R. M.; SCHWANEN, T. Tempo de deslocamento casa-trabalho no Brasil (1992-2009): diferenças entre regiões metropolitanas, níveis de renda e sexo, Brasília, DF: Ipea, p. 7-28. 2013. (Texto para discussão, n. 1.813).

RAMBAUD, Placide. Société Rurale et Urbanisation. Paris: Ed. du Seuil. $2^{a}$ ed. 1973. 343p.

RAVENSTEIN, E. G. As leis da migração. In: MOURA, Hélio Augusto de (Coord.). Migração Interna: textos selecionados. Fortaleza: Banco do Nordeste do Brasil. 1980. p. $19-88$. 
REICHARDT, C.S; COOK, T. D. Beyond qualitative versus quantitative methods. In: COOK, T. D; REICHARDT, C.S. Qualitative and Quantitative Methods in Evaluation Research. Londres: Sage. 1979. p. 7-30.

SOUSA, M. T. R. Mobilidade e Acessibilidade no espaço urbano. Sociedade \& Natureza, Uberlândia, v.17, n. 33, p. 119-129, dez. 2005. Disponível em:< http://www.seer.ufu.br/ index.php/sociedadenatureza/article/viewFile/9206/5668>. Acesso em: 14 nov. 2015.

SOUZA, M. F. Temporalidades: proposta para uma agenda de pesquisa em Ciências Sociais. Revista de Ciências Sociais, Paraíba, n. 34, p.11-18, abr. 2011. Disponível em: < http://periodicos.ufpb.br/ojs/index.php/politicaetrabalho/article/view/12181/ 7046>. Acesso em: 23 nov. 2015.

STROPASOLAS, V. L. O mundo rural no horizonte dos jovens. Florianópolis: Editora da UFSC. 2006. 346 p.

URRY, J. Mobilities. Cambridge: Polity Press, 1a Ed. 2007. 336 p.

VASCONCELLOS, E. A. Transporte urbano, espaço e equidade: análise das políticas públicas. São Paulo: Annablume, 2001. 218 p.

VEIGA, J. E. A dimensão rural do Brasil. Estudos Sociedade e Agricultura, Rio de Janeiro, v. 12, n. 1, p. 71-94, abril. 2004. Disponível em:< http://r1.ufrrj.br/esa/V2/ ojs/index.php/esa/article/view/246/242 >. Acesso em: 07 mar. 2013.

ZANON, R; MORETTO, A. C; RODRIGUES, R. L. Envelhecimento populacional e mudanças no padrão de consumo e na estrutura produtiva brasileira. Rev. Bras. Estud. Popul, São Paulo, v.30, p. 45-67. 2013. Disponível em: <http://www.scielo.br/ scielo.php?pid=S010230982013000400004\&script=sci_arttext $>$ Acesso em: 19 set. 2015 . 